\title{
Structuring the Smartphone Industry: Is the Mobile Internet OS Platform the Key?
}

\author{
Martin Kenney • Bryan Pon
}

Received: 3 January 2011 /Revised: 1 February 2011

Accepted: 3 April 2011 /Published online: 7 June 2011

(C) Springer Science+Business Media, LLC (outside the USA) 2011

\begin{abstract}
With the launch of the original iPhone, Apple redefined the "smartphone" product category and accelerated the convergence of traditional mobile telephony, Internet services, and personal computing into a new industry. As these sectors merge into a single device, formerly separate industry architectures and their constituent firms are being forced into direct competition. We test theories of industry architecture and technological platforms regarding their ability to explain the strategies of key entrants in navigating the transition. We analyze in detail the actions and strategies of four major competitors, including Apple, Google, Microsoft, Nokia, and, more briefly, Research in Motion and $\mathrm{HP} /$ Palm, from the framework of technological platform theory. Our analysis suggests that currently some competitors are following traditional platform strategies, but that Google and Apple appear to have adopted strategies at odds with platform literature. We examine how the dynamics of this convergence may lead to a reconsideration of certain tenets of platform theory.
\end{abstract}

Keywords platforms $\cdot$ industry structure $\cdot$ smart phones $\cdot$ android $\cdot$ iPhone

JEL Classification $\mathrm{L} 63 \cdot \mathrm{L} 86 \cdot \mathrm{L} 96$

\section{Introduction}

The convergence of mobile telephony, Internet services, and personal computing is resulting in the emergence of the smartphone and the "mobile Internet" (Ishii 2004; Funk

M. Kenney ( $\square)$

Department of Human and Community Development, University of California, One Shields Avenue, Davis, CA 95616, USA

e-mail: mfkenney@ucdavis.edu

B. Pon

Geography Graduate Group, University of California, 133 Hunt Hall, One Shields Avenue, Davis, CA 95616, USA 
2001). Information and communications technology (ICT) firms whose locus of competitive strength was centered in only one of these sectors are entering a new competitive landscape that is redefining and eroding the boundaries between software, hardware, and services. The key firms competing in this new market have each been a market leader in their original industry, and therefore bring previously successful firm recipes and particular core competencies to their smartphone efforts. Analysis of the extent to which firms are trying to leverage their existing assets and strategies to capture market share and value in the smartphone industry may be instructive in understanding how firms create and control value during periods of industry convergence. During such convergences firms must leverage and extend competencies, as they seek to shape the new value chain configuration and position themselves to capture as much of the total value created. The emerging smart phone industry provides an ideal case study for examining firm strategy in a moment of convergence.

The interest is understandable. Today more than 1.3 billion mobile phone handsets are being sold annually, and in 2010 smartphones made up almost $20 \%$ of that total (Gartner 2011; Ahonen 2010). In contrast to standard mobile phones, "smartphones" are powerful computing devices offering traditional wireless voice service as well as native software applications and, perhaps most importantly, the ability to connect to and run a myriad of Internet-based services including email, geo-location, streaming video, and social networking, while providing a good user experience. Sales of smartphones are increasing almost $100 \%$ per year, and total global sales volume is expected to surpass that of PCs by 2012 (Gartner 2010). By collapsing the boundaries between previously distinct devices, smartphones are subsuming sales of mobile phones entirely and, increasingly, netbook and notebook PCs. To complicate the landscape, the smartphone is not the only device at stake, tablets and ebook readers are emerging as key components of the mobile universe. Across all devices, total mobile revenues - including advertising, subscriptions, handsets, applications, and so on - are forecast to surpass \$1 trillion by 2014 (Gartner 2010). Given the rate at which smartphone are penetrating the market and component prices are declining by 2015 there will be, at least, 2 billion smart mobile devices in use globally.

The nature of the smartphone device and industry lends itself to analysis from a technology platform perspective. Scholars and management consultants have identified platform control as a key feature for business success in the ICT industries. Michael Cusumano, drawing upon his studies of Microsoft, Cisco, and Intel, concluded that the winner of technological competitions is "often who has the best platform strategy and the best ecosystem to back it up (Cusumano 2010, p. 34)." The opportunity to establish platforms often comes in the early phases of an industry's development or when a major technological/market discontinuity occurs. De novo firms and previously existing firms can use the discontinuities to enter a space and displace or subordinate previous incumbents or, even more cleverly, use new business models to transform the value capture equation. This paper explores the competition in the emerging smartphone operating system race, looking at value capture and customer lock-in strategies through the lens of industry architecture and platform theory. Other potentially important market characteristics were considered but not explicitly included. For example, the potential for anti-trust legislation or other legal challenges to firms' bundling of software, hardware, services, and content could alter strategies. Given the anti-trust lawsuits against Microsoft for bundling its browser to its operating system, it seems reasonable to expect regulatory scrutiny around any firm or platform that becomes dominant. The smartphone market may also be shaped by geographic considerations, both on the supply side as well as the demand side. Interestingly, the new firms to enter the space-Apple, Google, and HP (through Palm) — are all based in Silicon 
Valley, pulling the epicenter of mobile innovation away from Europe. Similarly, shifts in market demand away from the North American and European markets toward China, India and other countries introduce additional complexity and uncertainty for lead firms. In this paper, we pose the question of whether the platform literature and its emphasis on platform control is an adequate framework for understanding the complexities of the current struggle in the smartphone OS space.

\section{Platforms and industry architecture}

In the early platform literature, the platform was seen as a base architecture for product development with standard components that could be built upon (Cusumano and Suarez 2009). More recent research, especially on today's complex ICT industries, has argued that a platform is not solely a technology, but also the outcome of a set of business behaviors and relationships between actors in an ecosystem. This ecosystem for modern hightechnology platforms is characterized as having high levels of interdependence between actors, as well as high potential for innovation by each actor (Gawer and Cusumano 2002; Gawer and Henderson 2007; Gawer 2009). As a result, even those firms with clear market dominance in one area-e.g., Nokia with handsets - are dependent on the innovation of complementary firms to maintain their leadership position. Hardware firms and software firms rely on each other to push technology forward. Even Apple and its relatively closed iOS depends upon thousands of application developers to continue to create desirable apps for end-users; those developers that create iPhone apps have bet on the iOS platform's success and must rely on Apple to maintain and update their access to its operating system for ongoing development. In this system the interdependence is not limited to the transactional, supply-chain flow of typical goods and services, but is also based on the strategic exchange and integration of innovation among primary firms and their complementors to advance the platform (Tee and Gawer 2009).

The platform owner usually has intellectual property rights to use as leverage over those building applications upon the platform. Depending upon the robustness of rights, this means that the platform owner may be able to appropriate some of the value created by the applications built by platform users - indeed, the platform owner may depend on such value-creation by complements. The platform owner may also use its power asymmetry to stimulate competition among complementary firms providing the same service, which can lower its costs and further fortify its position (Tee and Gawer 2009).

\subsection{The stack}

In ICT industries, firm strategies within a platform ecosystem are complicated due to different technological layers - the "stack" - that must work together for the device to function. For smartphones, the bottom of the stack is the handset and the specialized components that deliver its functionality, including the CPU, graphics chip, cellular/wi-fi chips, Bluetooth, GPS, and camera. On top of the hardware is the operating system, which then has native applications installed on it. With Internet access, smartphones also run online applications such as email, geo-aware mapping, search, productivity software, games, social networking, and more. The question for platform sponsors at different locations in the stack is how they can extract a disproportionate share of value from the entire stack (Jacobides et al. 2006; Pisano and Teece 2007). In the PC industry, the OS and application layer have famously been the locus for value capture (e.g., Microsoft), though 
with the advent of the Internet the recent growth opportunities have been higher up in the stack, particularly Google's search function and other online applications. As more of these services move to "the cloud," and therefore become agnostic to the underlying OS (see Kushida and Zysman 2009), the one critical lever used by Microsoft to control and derive massive profits from the personal computer ecosystem will be diminished. In effect, there is a new platform in gestation, which will subsume other ecosystems and reorder value capture. The mobile Internet will be a critical battleground in this reordering. Figure 1 illustrates the industry stack and indicate where the key firms are attempting to capture value. Notice the two most successful new entrants, Apple and especially Google, have business models allowing them to capture value higher up in the stack by offering valueadded services, advertising, and revenues from content and application purchases.

\subsection{Customer lock-in}

While value may be captured in a certain location on the stack, the lock-in may occur in another layer of the stack. Platform strategies often include, or are even predicated upon, "locking in" more than one layer of the stack through switching costs or other market barriers (see Fig. 2). For example, though most persons attribute Microsoft's dominance to its control of the Window's OS, equally, or perhaps more important, is the Microsoft Office productivity suite, which is the consumers' connection to Microsoft and is likely more important for the mindshare lock-in than the desirability of Windows. Interestingly, though Google has points of lock-in, these seem considerably less powerful than that of Microsoft. The true strength of Google's lock-in may be in the very diversity of services it provides. For some customers that might be search, Gmail, and Google maps, while for another customer it might be Gmail, Google Scholar, and YouTube. Each user's commitment can be to a different set of services; and all provided by the data center. With smartphones, lock-in and switching costs depend on the industry architecture for that specific market. For example, in the U.S., with its subscription-based plans, customer switching costs are high due to contracts (typically 1-2 years with early termination fees) and

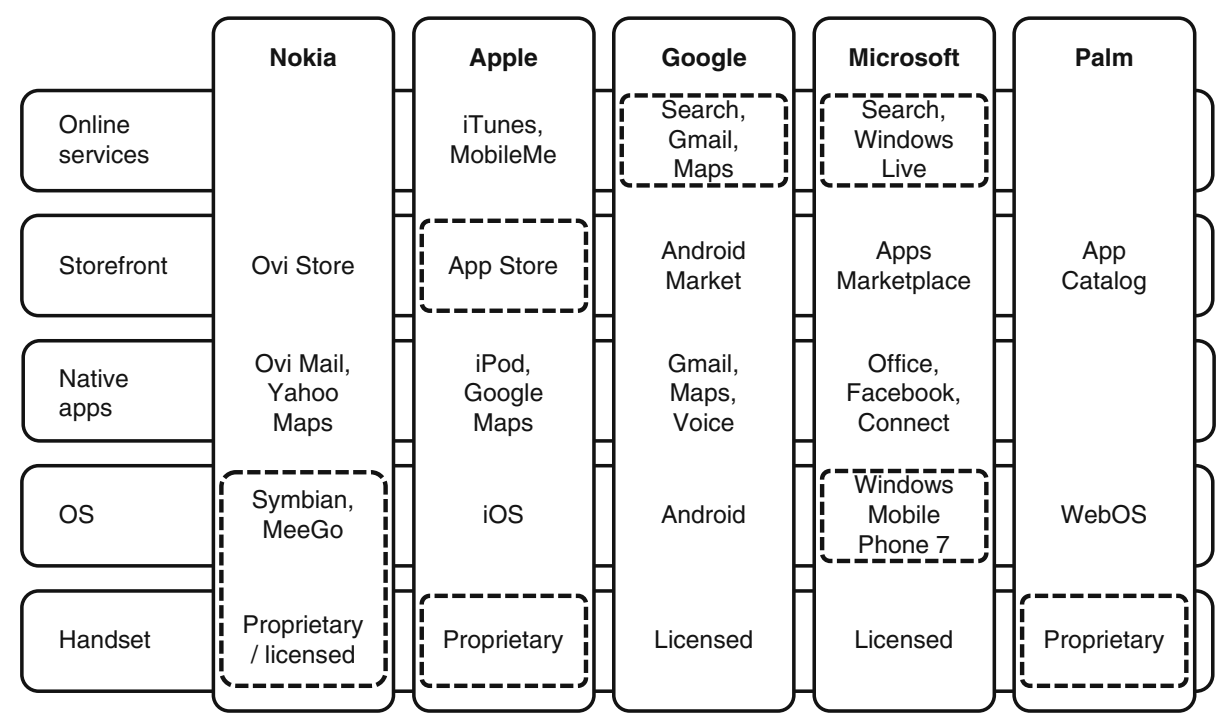

Fig. 1 Where firms capture value 


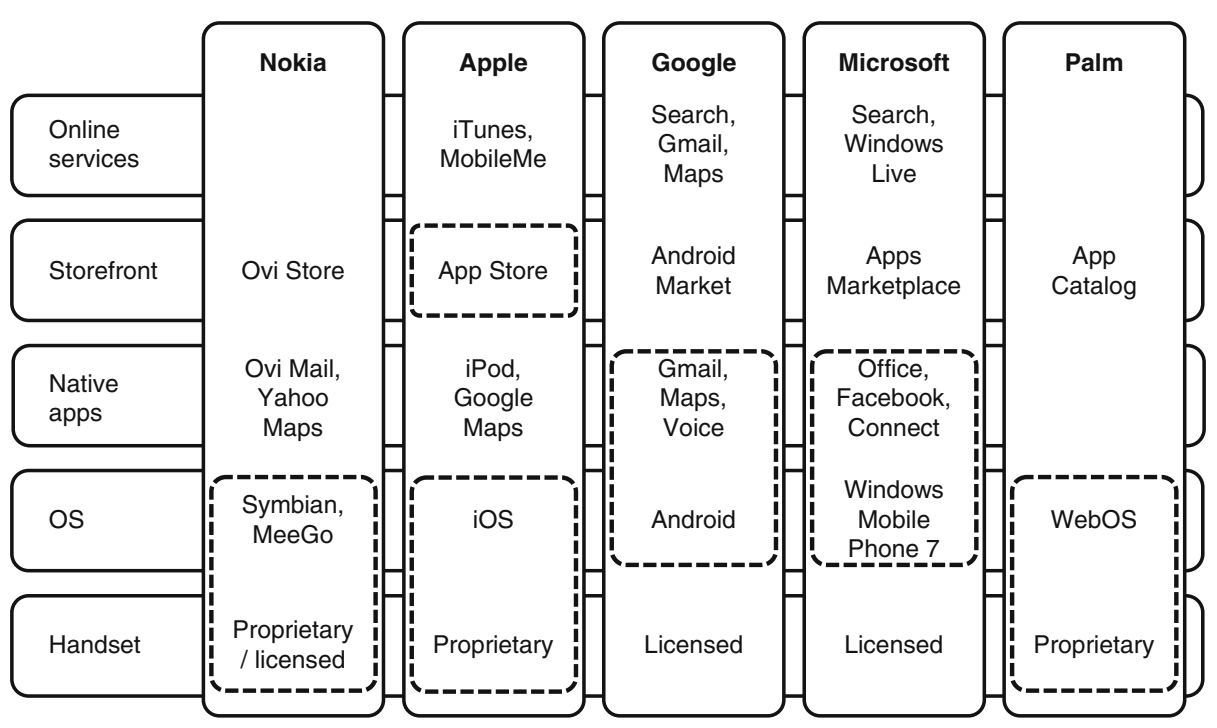

Fig. 2 Where firms lock in customers

incompatible network technologies (e.g., CDMA and GSM). Researchers have estimated these customer switching costs in the U.S. to be \$230 (Cullen and Shcherbakov 2010), however, in pre-paid markets this would be significantly less.

The key firms in the smartphone industry bring different core strengths that determine where customer lock-in occur (see Fig. 2), though this will likely vary somewhat based on user profile. While Google shows a discrepancy between where it captures value and where it locks in users, Apple appears more aligned - the iTunes and the App Store have become a significant source of revenues for Apple through the sale of apps, music, TV shows, and other media. And as a one-stop shop for accessing applications and media, linked to a personal account with payment information, the ease-of-use and features of iTunes/App Store create stickiness with users. We explore the concepts of lock-in and value capture in more detail in the firm analyses below.

\subsection{Industry architecture}

Switching costs and lock-in strategies in the smartphone industry will depend in part on what has been called the industry architecture. Jacobides et al. (2006) concept of industry architecture is based upon identifying the different roles played by firms in an industry, and how those roles allocate the division of labor and share of the total value generated. The rules governing who does what, and how firms collaborate, can be "designed" in the sense that they come from regulation, standards, and so on, or "emergent" in that they evolve from social and economic norms (Jacobides et al. 2006). As Tee and Gawer (2009) showed in their case study of the Japanese cell phone system i-mode, these architectures can be important determinants of how firms are able to establish and promote platforms, as they provide the background structure to the platform ecosystem.

The United States, with its large smartphone market, has an industry architecture that is important to consider. For example, the network carriers in the U.S. play a prominent role in everything from customer engagement to handset development. In Jacobides' language, there are designed factors (e.g., multiple incompatible network standards, primarily GSM 
and CDMA) and emergent factors (culture of subscription-based usage plans), both of which increase switching costs and lock-in customers, that contribute to this. Carriers such as Verizon and AT\&T not only operate the network, but also sell handsets and provide content, in essence vying to be a one-stop shop for end-users in their mobile experience. The degree to which handset manufacturers must work with the carriers is reflected in the pricing for smartphones in the U.S. - typically $\$ 200$ or less if the customer signs up for a 1- or 2-year contract, a fraction of the full retail price. This subsidization of the purchase price, which the carrier earns back through monthly subscription revenue, creates a very high barrier to entry for independent retailers or handset manufacturers wanting to sell standalone smartphones direct to customers. ${ }^{1}$

Carriers in the U.S. typically set their product requirements and OEM product development is carried out accordingly. Apple was the exception, as U.S. carriers (AT\&T and now Verizon) accepted the Apple product as designed. ${ }^{2}$ In addition to the expected and necessary collaboration - for example, between carriers and chip designers to optimize network performance - carriers are making decisions about how data is consumed on their networks (e.g., charging for data plans) and what services can be used (e.g., Skype or other VoIP clients). Further, as part of their effort to lock-in customers, carriers seek to provide unique services, such as proprietary content or applications that distinguish the phones that they sell. A key question is whether firms that focus on the lucrative U.S. market, and who must therefore operate within the roles and influences of the industry architecture there, must adapt their strategies in other markets where the architecture is different.

As the key smartphone firms establish their ecosystems and platforms, one expects each to develop as part of its strategy how it will lock in users and profits to its platform. Compared to the PC industry, the smartphone industry has more diverse actors, with higher levels of interdependence, and more technological uncertainty due to the early stage of its development and the rapid technological innovation. The key firms that have developed smartphone operating systems (Table 1) in bids to control this new space are detailed in the next section. Some are pursuing a fully vertically integrated approach - in which the OS and hardware are produced within the firm - while others have developed "open" operating systems meant to be licensed by a wide range of handset makers. ${ }^{3}$ These strategies and others that are intended to lock-in users and capture value for the firm are looked at in more detail at the firm level.

\section{The competitive landscape}

The different business models and strategies for value capture in the smartphone industry reflect the diverse backgrounds and historical core competencies of the competing firms. The incumbents, such as Nokia and Palm/HP, hail from the mobile phone and personal digital assistant (PDA) industries, while newer entrants such as Apple and Google come from the personal computing and Internet worlds. Nokia, the longtime market leader, still

\footnotetext{
${ }^{1}$ Google tried to circumvent the carrier's monopoly on handset sales with its own handset, the Google Nexus One, which was to be sold online, unlocked, online for $\$ 99$. But reported resistance from the carriers, who Google depends on to sell other handsets with Android, killed the project. See http://techcrunch.com/2010/ 09/10/google-nexus-one/.

${ }^{2}$ The authors thank Timo Seppälä for making this point.

${ }^{3}$ Distinct from the earlier computing platforms, all of these competing smartphone platforms eventually used the same CPU architecture, that of UK-based ARM. The ARM design is licensed to all manufacturers. Given ARM's dominance in the market, there was a convergence in CPU architecture despite divergence of software architecture.
} 
Table 1 Key smartphone platforms

\begin{tabular}{|c|c|c|c|c|c|c|}
\hline Operating system & Sponsor & Founded & $\begin{array}{l}\text { First } \\
\text { shipped }\end{array}$ & $\begin{array}{l}\text { Application } \\
\text { store }\end{array}$ & Type & Device customers \\
\hline Symbian & Symbian Ltd. & 1998 & $1999 a$ & & $\begin{array}{l}\text { Proprietary } \\
\text { licensed }\end{array}$ & $\begin{array}{l}\text { Nokia, Sony } \\
\text { Ericsson, } \\
\text { Samsung }\end{array}$ \\
\hline Symbian & $\begin{array}{l}\text { Symbian } \\
\text { Foundation; } \\
\text { Nokia }\end{array}$ & 2009 & & & Open source & Nokia \\
\hline $\begin{array}{l}\text { Windows CE, } \\
\text { Windows Mobile, } \\
\text { Windows Phone } 7\end{array}$ & Microsoft Corp. & & $2002 a$ & $\begin{array}{l}\text { Windows } \\
\text { Marketplace } \\
\text { for Mobile }\end{array}$ & $\begin{array}{l}\text { Proprietary } \\
\text { licensed }\end{array}$ & $\begin{array}{l}\text { HTC, Samsung, } \\
\text { Toshiba, HP,? }\end{array}$ \\
\hline Palm OS & $\begin{array}{c}\text { Palm, Inc. later } \\
\text { Palm Source }\end{array}$ & 1992 & $1998 \mathrm{a}$ & & $\begin{array}{l}\text { Proprietary } \\
\text { licensed }\end{array}$ & $\begin{array}{l}\text { Palm, } \\
\text { Handspring, } \\
\text { Samsung, } \\
\text { Kyocera }\end{array}$ \\
\hline WebOS & Palm, Inc. & & 2009 & App Catalog & Proprietary & Palm \\
\hline BlackBerry & $\begin{array}{l}\text { Research in } \\
\text { Motion }\end{array}$ & 1995 & 2002 & $\begin{array}{l}\text { BlackBerry } \\
\text { App World }\end{array}$ & Proprietary & RIM \\
\hline iOS & Apple Inc. & & 2007 & $\begin{array}{l}\text { iPhoneApp } \\
\text { Store }\end{array}$ & Proprietary & Apple \\
\hline Linux Mobile & $\begin{array}{l}\text { LiMo } \\
\text { Foundation }\end{array}$ & 2006 & & & Open source & \\
\hline Android & $\begin{array}{l}\text { Open Handset } \\
\text { Alliance; } \\
\text { Google }\end{array}$ & 2007 & 2008 & Android Market & Open source & $\begin{array}{l}\text { HTC, Motorola, } \\
\text { Sony Ericsson }\end{array}$ \\
\hline Android & $\begin{array}{l}\text { Open Handset } \\
\text { Alliance; } \\
\text { Google }\end{array}$ & 2007 & 2008 & Android Market & Open source & $\begin{array}{l}\text { HTC, Motorola, } \\
\text { Sony Ericsson }\end{array}$ \\
\hline
\end{tabular}

${ }^{a}$ Before the first smartphone, earlier versions of the OS were used for PDAs

dominates the industry in terms of handset sales, and has been the primary supporter of the correspondingly dominant Symbian operating system. However, Nokia is quickly losing smartphone market share to new competitors, especially Apple and Google, and the current state of the market (see Table 2) can be seen as a battle between an entrenched global incumbent and newcomers to the mobile space.

The key firms with competing smartphone operating systems are Nokia (Symbian/Meego and now Windows Phone 7 or WP7), Apple (iOS), Google (Android), Research In Motion (Blackberry), ${ }^{4}$ Palm/HP (WebOS), and Microsoft (WP7). While Nokia, RIM, Apple, and

\footnotetext{
${ }^{4}$ We largely omit Research in Motion (RIM) in this paper because its Blackberry operating system targets the enterprise sector. While this market is large and significant in the United States, RIM's market share is in steady decline, from a high of $43 \%$ in Jan. 2010 to 31\% in Jan. 2011 (ComScore). This decline is due in part from recent updates to iOS and Android that have enabled better enterprise support: iOS and Android devices can now work directly with Microsoft Exchange, eliminating the need for companies to invest in separate RIM software and support. As a result, $40 \%$ of new iPhone activations through AT\&T are for enterprise customers. The entrance of Apple and Google into the mobile enterprise market can be seen as part of a larger trend of consumer-focused technology driving enterprise applications and services (for example, social networks, micro-blogging, and instant messaging leading to Convofy, Salesforce.com's Chatter, SocialCast, and many more). This is clearly the case with smartphones, where most of the innovation has come from the consumer side. For these and other reasons, the authors decided to focus the paper on those firms targeting the consumer market.
} 
Table 2 Smartphone industry overview

\begin{tabular}{|c|c|c|c|c|c|c|c|c|}
\hline & Status & Industry & Location & OS & $\begin{array}{l}\text { Status of OS to } \\
\text { phone makers }\end{array}$ & Cost & Mfg? & Profit model \\
\hline Nokia & $\begin{array}{l}\text { Leader } \\
\text { Incumbent }\end{array}$ & $\begin{array}{l}\text { Mobile } \\
\text { phones }\end{array}$ & Finland & $\begin{array}{l}\text { Symbian } \\
\text { Indep. }\end{array}$ & $\begin{array}{l}\text { Opened recently } \\
\text { to all, but only } \\
\text { Nokia }\end{array}$ & $\begin{array}{l}\text { Now } \\
\text { free }\end{array}$ & Yes & $\begin{array}{l}\text { Handset } \\
\text { and trying } \\
\text { downloads }\end{array}$ \\
\hline Apple & New entrant & $\mathrm{PC}$ & SV & Own & $\begin{array}{l}\text { Not open, } \\
\text { but APIs }\end{array}$ & $\mathrm{n} / \mathrm{a}$ & $\begin{array}{l}\text { Contract } \\
\mathrm{mfg} .\end{array}$ & $\begin{array}{r}\text { Handset and } \\
\text { downloads }\end{array}$ \\
\hline Google & New entrant & Internet & SV & Own & $\begin{array}{l}\text { Open to all } \\
\text { to use }\end{array}$ & Free & No $\mathrm{mfg}$. & Advertising \\
\hline Motorola & $\begin{array}{l}\text { Declining } \\
\text { Incumbent }\end{array}$ & $\begin{array}{l}\text { Mobile } \\
\text { phones }\end{array}$ & U.S. & $\begin{array}{r}\text { Agnostic } \\
\text { Adopter } \\
\text { Android }\end{array}$ & Adopter & $\mathrm{n} / \mathrm{a}$ & Yes & Handset \\
\hline Samsung & $\begin{array}{l}\text { Growing } \\
\text { Incumbent }\end{array}$ & $\begin{array}{l}\text { Mobile } \\
\text { phones }\end{array}$ & Korea & $\begin{array}{r}\text { Agnostic } \\
\text { Adopter } \\
\text { Android }\end{array}$ & Adopter & $\mathrm{n} / \mathrm{a}$ & Yes & Handset \\
\hline HTC & $\begin{array}{l}\text { Growing } \\
\text { Incumbent }\end{array}$ & $\begin{array}{l}\text { Mobile } \\
\text { phones }\end{array}$ & Taiwan & $\begin{array}{r}\text { Agnostic } \\
\text { Adopter } \\
\text { Android }\end{array}$ & Adopter & $\mathrm{n} / \mathrm{a}$ & Yes & Handset \\
\hline
\end{tabular}

Palm/HP are vertically integrated with their own handsets, operating systems, and application stores, Google and Microsoft appear focused on licensing their OS to multiple partners. Handset-only manufacturers such as Samsung, LG, Sony Ericsson, Motorola, and HTC must make strategic OS licensing decisions in order to stay relevant, while network carriers face different challenges in trying to establish and maintain competitive advantage in what may be a "race to the bottom" to supply the physical network infrastructure.

Each firm must develop and participate in a complex mobile phone ecosystem required for successful propagation of their preferred solution. This will require forging strategic partnerships and alliances with varying degrees of control and influence and also allowing spaces or providing platforms upon which other firms can build. With different OS competitors adopting widely disparate approaches to capturing value, there is significant uncertainty over how the technology and industry will evolve.

\section{Historical firm trajectories}

\subsection{Nokia}

Relying on its vertically integrated manufacturing capabilities and strong relationships with network carriers around the world, Nokia rode the wave of mobile phone adoption to become the dominant mobile handset producer. However, despite strong sales of lower-end handsets in developing countries, its share of the global market has steadily declined from a peak of approximately $60 \%$ of all handsets to $30 \%$ in 2010 . By the end of 2007 , Symbian was the OS for approximately $65 \%$ of all smartphones, compared to $12 \%$ for Windows and $6.5 \%$ for the iPhone. Nokia alone held about $53 \%$ of the global smartphone market (West and O'Mahony 2008). By the end of 2010, however, only $37 \%$ of all smartphones were running Symbian, compared to 26\% for Android and 17\% for iOS (Gartner 2010).

As the dominant manufacturer, Nokia was entirely aware of the coming convergence of the Internet and the mobile phone. Its response was to join in 1998 the three-largest 
handset makers at the time, Nokia, Ericsson, and Motorola, and the English firm Psion, to create a new company that would develop a smartphone-specific operating systemSymbian - that they would freely license to a wide range of handset makers (West and Mace 2010). Nokia's strategy was to create a common standard that would eliminate platform competition and help ensure that its dominance was not threatened through a standards change it was not involved in. Because Nokia made its profits by selling handsets and base stations, it sought to neutralize potential threats to value capture by supporting an open-source standard. Once it began backing Symbian, Nokia immediately accounted for more than $80 \%$ of Symbian's handset sales and the majority of all smartphone sales until 2008; currently Nokia captures approximately $31 \%$ of the smartphone handset market (Nokia Q4 2010). In June 2008, Nokia bought control of Symbian and began distributing its operating system as open source software, before announcing in 2010 that the most advanced Nokia smartphones would no longer run Symbian, but instead a new OS called Meego, but in early 2011 abandoning this for WP7. Meego was a collaboration between Nokia and Intel, merging Nokia's Maemo and Intel's Moblin projects into a single, open-source effort. Based on Linux and managed in part by the Linux Foundation, Meego was slated to be the most open of all the current smartphone operating systems.

Given its dominance in the Symbian ecosystem and its position as the global leader in smartphone sales, Nokia's decision to phase out development of the Symbian OS was a major turning point. By leaving behind a legacy operating system in favor of new technology and then dropping that initiative, Nokia hoped to catch up with its competitors' much younger operating systems. Microsoft has done the same by dropping Windows Mobile and starting over with WP7. Nokia's choice to adopt WP7 is recognition, as Teece et al. (1997) observed that complementary assets can be extremely important during technological transitions. Nokia, as the global cell phone leader has significant complementary assets including powerful connections to operators, extremely efficient supply chain management including their own global manufacturing facilities (see Rouvinen in this volume), and enormous reservoirs of wireless knowledge to leverage this risky transition. The question is whether the smartphone transition will allow the utilization of these complementary assets.

It was from the two nations where Nokia failed to have meaningful participation from where its most significant manufacturing competitors would come. As has been described by Funk (2001; 2003), while Nokia did not have a meaningful presence in Japan, for a number of reasons Japanese firms, though often introducing the newest applications, were never successful in exporting (Kushida and Zysman 2009). In contrast, two Korean firms, Samsung and LG, eagerly licensed new technologies such as Qualcomm's CDMA technology and deliberately followed a low-cost mass production strategy that defeated most of Nokia's important Western mobile phone competitors. Nokia, however, was able to counter this strategy by selling high-end phones in Europe, in particular, but also in developing nations, while also developing a low-cost production capacity in developing nations, thereby meeting the Korean competition directly.

The other threat that materialized was the one that was less obvious. This was from the U.S., but more particularly, Apple Computer and the iPhone, which seamlessly integrated the Internet into a mobile phone. Nokia recognized both the design excellence of the iPhone software, which may have been imitable, but it was the plethora of third-party application providers and media content owners connected through a single marketplace-iTunes - that created a dynamic software-based supplier ecosystem which Nokia had never before experienced. This blind spot to changes in the U.S. market may have been, in part, due to 
the lack of a significant presence in Silicon Valley. Ultimately, this resulted in a competitive challenge that could not be responded to directly by an internal corporate strategy.

\subsection{Apple}

The first significant new entrant to the emerging mobile Internet space was Apple, which in 2007 introduced the Apple iPhone. It catalyzed a shift in the architecture of the mobile phone industry and set the standard in two ways. First, it provided a fully functional web browser that allowed users to escape previous operator-specific silos of mobile content by linking them directly to the infinitely larger and more diverse Internet value networks. ${ }^{5}$ In effect, it collapsed the boundaries between the mobile device and the Internet with its enormous content. Secondly, leveraging the iPod ecosystem, but going far beyond it, the iPhone created a platform sufficiently open and attractive to create an ecosystem of application providers with 250,000 iPhone-specific applications that encouraged billions of downloads. Many see the innovations by iPhone application developers as a key driver of user adoption (Martinez-Salazar 2010). Despite Apple's vertically integrated approach — and initial strategy of exclusive carrier contracts - it identified the enormous demand for easyto-use mobile Internet terminals. Apple catalyzed and capitalized upon the subsumption by the Internet of the originally separate mobile phone world. Apple accomplished two seemingly contradictory feats simultaneously: 1) It leveraged users' desire to have access to the entire Internet and their Internet-based applications on a handheld device, and 2) it created a platform upon which developers could build iPhone-specific applications that it would control and from which it could extract a rent. Apple effectively re-created a Macintosh-like user system without the power that Microsoft exerted over Apple through its control of Microsoft Office. The iPhone also challenged the traditional mobile phone manufacturers who were delivering an inferior Internet experience and, outside of Japan and, to a lesser degree, China and Korea, had not been able to create a dynamic phonespecific applications ecosystem. Finally, in North America and Europe, neither phone makers nor carriers had platforms that were attractive to independent developers.

In many ways, the success of the iPhone is quite unremarkable and strategically interesting only because it had early mover advantage and an excellently engineered product. From this perspective, the iPhone success is a typical model of leveraging a previously successful platform, the Apple iPod, with its extant ecosystem, cachet, and market momentum, to enter the more contested market, mobile telephony, within which the existing dominant vendor, Nokia, has difficulty responding to the coming technological discontinuity. ${ }^{6}$ In this sense, Apple followed a platform "tipping" strategy across markets, from digital media player to smartphone (Gawer and Cusumano 2002). In contrast to the Christensen paradigm of entering in a low-end segment and working upwards, the iPhone enters the high-end of the market with a more functional product. Of course, part of having a successful product is its inherent quality and attractiveness to consumers. The corollary is that a large and growing market and market share attracts potential platform complementers. Finally, Apple has devoted followers, many of whom have significant technological capabilities and provide a large group of early adopters.

\footnotetext{
$\overline{5}$ For example, the very important Internet-based world of pornography, a powerful driver of early adoption and monetization, now became available to iPhone users. In the academic literature there has been little recognition of the importance of pornography in driving early Internet technology adoption.

${ }^{6}$ CM Christensen (1997)
} 


\subsection{Google}

As an advertising and Internet services firm, Google has an entirely different business model from most competitors in the smartphone industry, and this has a significant bearing on its current platform strategy. Google entered the mobile Internet from its dominating position in the PC-centric Internet world, but without in-house technology or competence in mobile, Google had to acquire an operating system. It bought the mobile software firm Android in 2007, later creating an industry consortium around the Android operating system. ${ }^{7}$ Android, which is free to license and selectively open, was immediately attractive to the weaker handset makers, particularly those in East Asia that were not strong software developers and did not have the market power to drive an OS into the mainstream. Their previous options were to pay Microsoft to use its mobile OS or adopt the Nokia-supported and -dominated Symbian OS. The rapid success of Android is testimony to the interest. In the 15 months since the first Android phone was sold, the OS has captured nearly $25 \%$ of the smartphone market (from Q3 2009 to Q3 2010 saw a year-on-year increase of 1,300\%) and won endorsements from most of the world's handset makers (Canalys 2010). Android's market share continues to increase and by February 2011 according to one market analyst had $33 \%$ of the total U.S. smart phone market (Comscore 2011).

Along with the iPhone and other mobile platforms, Android has fueled adoption of mobile data services and mobile usage of existing Internet services, including Google's. Android is therefore key in Google's efforts to expand the scope of its mobile Internet offerings and user acceptance to include not just search, but also video, email, shopping, maps, and other offerings. As with Apple, Google has spent considerable effort to promote the Android platform and encourage innovation from the ecosystem, especially with developers, and has registered over 100,000 Android-specific applications in 2 years.

The early success of the Android OS has significant implications for other actors in the stack. With Android as the hook, Google threatens carrier efforts to create value-added services on top of the wireless Internet infrastructure they built, as Android phones are completely agnostic as to the system on which they operate. This differs, in this respect, from Apple, which signs contracts with a single mobile service provider, thereby providing the mobile service provider pricing power.

What Android did was enable entry by hardware makers without good software capabilities, as a royalty-free Linux-based Android has been adopted by all the major Asian handset makers, as well as Motorola and Sony Ericsson. What is forgotten is that in the U. S. market it initially had a similar effect for carriers. In October 2008, the first Android phones in the U.S. were sold by U.S. market also-ran, T-Mobile. Though the T-Mobile phone did well, in total market terms there was little penetration. There was however an important demonstration effect and this can be now seen as the other carriers have joined T-Mobile. In the U.S. market, in Q1, 2010 more Android handsets were sold than were Apple iPhones (RIM continued to be the leader). Of course, this was a function of a proliferation of models and a willingness by every other carrier to support Android phones.

\subsection{Microsoft}

Microsoft has long recognized that mobile computers were emerging, but has always had to contend with its desire to integrate and subsume these new devices into its Windows

\footnotetext{
$\overline{7}$ Android is eerily reminiscent of the young Microsoft, it secured when it purchased a startup.
} 
franchise. With the emergence of the PDA market, Microsoft introduced Windows CE operating system. Though never able to develop dominance similar to what it had achieved in PCs, as the PDA gradually merged with the cell phone to create the smartphone, Windows CE evolved into Windows Mobile, and finally the Windows Phone OS. While its initial target was its PDA licensees such as HP, it eventually gained modest market share from Asian handset makers (notably Korean's Samsung and Taiwan's HTC). They were drawn to Windows Mobile because they did not have their own smartphone OS. More recently, Windows Mobile's market share is slipping as most vendors using Windows Mobile have switched to Android, while BlackBerry and iPhone also gained market share.

The apparent inability of Microsoft to transition its PC dominance to the mobile Internet, may, at least in part, be attributed to its initial inability to secure a dominant position in the Internet world. While Cusumano and Yoffie (1998) analyzed Microsoft's defeat of Netscape in web browsers, what they could not foresee was that Microsoft would be unable to use Internet Explorer to extract greater value from the Internet. The browser became a free good and it would be Google that would use its search engine to become the dominant firm on the Internet - it was agnostic toward other browsers but favored Mozilla, an open-source alliance. Interestingly, with the release of the Chrome browser, Google appears to have turned on Mozilla.

In terms of smartphones and the mobile Internet, Microsoft did not develop a viable strategy for capturing significant market share, as there is little need for mobile applications to have deep interfaces with most Microsoft products beyond, perhaps, Outlook. In the reconfiguration of the computing ecosystem with the growth of the mobile Internet, Microsoft appears to be increasingly confined to the PC-centric world, and if the tablet computers are successful, the desktop may be its only real home, unless its initiatives such as the Bing search engine can gain sufficient market share to create a synergy with WP7. However, Microsoft seems committed to Windows Phone OS, and initial assessments of the first production release tend to regard Windows Phone OS v.1 as at least as good as iOS v.1 and better than Android v.1, though given the pace of improvement such advantages appear to be fleeting.

For Microsoft the question is how to develop the same type of dominant position that, for all intents and purposes, IBM bequeathed to them by accepting DOS (for a discussion of this, see Wallace and Erickson 1992). Their strategic challenge is to move the dominant Office franchise to the cloud and then extend it into the mobile space, recreating the OSOffice synergy that made them dominant in desktop computing? In the same way, as the incumbents have lost market share in every transition, such as from mainframes to minicomputers, then from minicomputers to work stations and personal computers, it is possible that the transition from personal computers to mobile devices could be the harbinger of a new changing of the industry architecture, successful business models, and dominant firms. Microsoft clearly has enormous financial and organizational resources and competencies, but whether these can be repurposed effectively, while protecting the enormously profitable current business model, is, at this time, indeterminate. What is clear is the Microsoft has become aware of what is at risk.

\subsection{Palm/HP}

The Palm WebOS offering for smart phones is an outgrowth of its strength in PDAs. However, in the transition to smart phones it had to update its operating system, hence the WebOS. When it was introduced in 2009 to favorable reviews, an inferior handset raised concerns about its survival, crippling adoption of both the new platform and its phones. The 
result was that it rapidly lost market share to Apple and Android. Moreover, it never had significant market share outside North America. This meant that Palm and its OS appeared to be entering the downward spiral characterizing increasing returns network industries.

In late April HP purchased Palm for $\$ 1.2$ billion with the express purpose of acquiring WebOS and Palm's many patents. However, how Palm fits into HP's mobility strategy is unclear. It is possible that HP (the world's largest PC maker) will abandon Windows Mobile, thereby weakening Microsoft's mobile efforts. As a tactical move, HP could open the Palm WebOS to all, possibly slowing the Android adoption rate. One difficulty with such a strategy is that HP will control the evolution of WebOS, so all other handset producers might reasonably expect that they would be disadvantaged (similar to Nokia's current position with Symbian). The applications providers are likely to question whether HP can develop a user base large enough to monetize their investment. The strength of WebOS is that it now has a powerful sponsor that can subsidize its evolution. The question is whether, without other adherents to the platform, WebOS can be carried by HP alone.

\section{Smartphone platform strategies}

This section reviews key platform strategies from the literature, and examines them in the context of the current competition within the smartphone industry. A key question is whether all firms currently offering smartphone operating systems are in fact pursuing a traditional platform business model.

\subsection{Open versus closed platforms}

In theory, platform firms are dependent on an ecosystem of complementary firms for innovations that drive the platform forward (Tee and Gawer 2009). For products with operating systems, this has typically meant licensing the OS to multiple partners in order to build up the ecosystem of complementers and drive adoption. As the de facto owner of the Symbian operating system, Nokia has generally followed this approach in promoting what is currently the dominant smartphone platform. It created the Symbian Foundation with other key firms (e.g., Motorola, AT\&T, Sony-Ericsson, Vodafone) to actively promote the platform through licensing and collaborative development. Nokia encouraged widespread adoption of the Symbian OS, working with application developers, handset manufacturers, and network carriers to support new innovations that took advantage of the Symbian platform. Nokia licensed the OS to other handset manufacturers even though it was also selling its own proprietary handsets. This strategy and conceptual model of a platform is predicated on a significant amount of platform openness - even though Nokia had the largest stake in the Symbian coalition, the other partners were able to fully interface with the technology and play a part in its evolution. According to Gawer and Cusumano (2002), "a true platform ...is no longer under the full control of the platform owner, even if it contains some proprietary elements."

This requirement for openness casts doubts on whether Apple, with its famously tightly managed system, has ever meant iOS to become a platform in this traditional sense. Certainly Apple depends on an ecosystem of complementary firms to make technological advances in key product components such as screens, camera sensors, antennas, and chips. And it relies on independent application developers to produce innovative, desirable apps to run on iOS, and network carriers to invest in higher-capacity infrastructure to support faster data transfer. But to ask Gawer and Cusumano's definitional question-Is iOS still under 
the full control of the platform owner? - the answer would seem to be a resounding yes. In pursuing its vertically integrated, closed system, Apple maintains high levels of control over the entire product ecosystem, from the handset and OS to the available applications and even the network. While this "walled garden" strategy probably does, as Apple claims, provide a more effective and cohesive user experience, it also limits the external innovation and scale that can come from more open platform licensing strategy. In their 2007 article, Gawer and Cusumano look at the rising popularity of the iPod, and specifically address the question of whether Apple is a product or a platform company. Their assessment was that Apple's closed systems allow it to focus on creating great proprietary products that define new product categories, and that as long as there was no more open platform offering serious competition, this closed platform strategy made sense. Three years later we can see that while iOS redefined the category and is still a leader, Apple's strategy faces considerable pressure from the open Android platform, especially as lower-cost handsets and developing country markets emerge as growth areas. If Apple were pursuing standard platform strategy, we might expect it to respond to the Android threat by opening its platform in order to increase the number of iOS devices and retain market share. However, Apple's closed ecosystem may be focused on longer-term goals: As new device categories emerge, Apple's ability to maintain a cohesive mobile user experience across the iPod, iPhone, and iPad may be an advantage over other mobile operating systems also trying to cross device boundaries - issues with application compatibility, OS forking, etc. are only likely to multiply as the various smartphone manufacturers venture into tablets, notebooks, TVs, onboard vehicle displays, and more.

Google seems to be taking a very different approach from Apple - a more open and at first glance, more traditional platform strategy. By promoting Android as an open platform ${ }^{8}$ and licensing the OS for free to handset manufacturers around the world, Google is quickly building the number of devices running Android. While the short-lived Nexus One and the recently introduced Nexus S are both Google-branded handsets, Google is not in the handset business, and instead seems to use these high-performing devices as demonstration hardware designed to highlight the newest Android OS features. As a relative latecomer to the smartphone market, Google faced entrenched opposition from Nokia/Symbian as well as from quickly rising Apple/iOS. Its open, free licensing approach with Android is intended to build market share as quickly as possible, with the goal of taking advantage of "network effects" - whereby for each additional user of a platform, the value of the platform to all users increases (Cusumano and Suarez 2009). However, this pricing scheme (free) runs counter to the Windows practice of charging for a license or iOS and Palm WebOS that are closed. A Symbian license is free as will be the case with Meego (if it is introduced). What is unclear is what are Google's longer-term goals for Android. Google currently does not need to charge for Android because its core search advertising business supports Android and other ventures that are unprofitable. But licensees and other partners may wonder whether Google will continue development and support of Android if it remains a free product that doesn't generate profits - if the advertising revenue dries up, will Google keep investing in a product that only costs money?

\footnotetext{
${ }^{8}$ While considerably more open of a platform than Apple's iOS, critics will point out that Android is not completely "open source" in the same way that Linux or other platforms are open source, meaning that core development is not transparent and independent developers cannot contribute to the process. Judging by the rapidly increasing number of independent apps that have been developed for Android, this distinction seems less important.
} 
Microsoft seems to be following its legacy strategy from the PC industry, and is perhaps somewhere in the middle between Apple and Google in this regard. It is charging device manufacturers to license the WP7 OS, but it is encouraging widespread development and integration with its platform. Of course, the openness of the platform alone is not the only consideration for platform participation by complementors - as with WebOS, developers and handset manufacturers may not be inclined to invest if the user base is not present.

\subsection{Lock-in and value capture}

In contrast to other smartphone firms, Google is a service provider-blogging, maps, news, books, scholar, photo sharing, finance, shopping, email, apps, YouTube and Google Voice. Interestingly, none of these alone has a powerful lock-in, and there is no powerful synergy between them except for the fact that all of them drive the user toward Google's search function. In terms of value capture and the smartphone stack, Google earns no revenue from the device, OS, or basic apps such as email or maps. Just as with the PC, Google's revenues come from search advertising delivered from the cloud. The implications of this are interesting within the context of technology platforms. Other firms with smartphone operating systems are vying for customer lock-in and value capture at various levels of the stack. But because Google essentially captures value in the cloud, it is almost agnostic as to what every other level of the stack is. In fact, it may be in Google's interest to turn everything else into a commodity speeding and deepening diffusion of the smartphones and other mobile devices. It doesn't care if the handsets being sold are HTC or Samsung. And, importantly, it may not even care if the handset is running Android or iOS. What Google does care about is ensuring that its ads are served on as many mobile devices as possible. Therefore, instead of relying on Android as a direct revenue-generator, Google seems to be currently using it to 1) build the overall market for mobile devices, and 2) check the runaway growth of iOS. To increase the overall market, it makes sense that Google would license Android for free as a way to enable device manufacturers to design and build quality smartphones quickly and inexpensively. The lack of OS licensing fees are especially important in the mid- and lower-end of the price range where margins are slimmer, and where significant growth is expected. But Google is not just concerned with building the total number of smartphones, because if enough of those smartphones are running iOS, then the possibility arises that Apple would feel empowered to make changes about the default search engine on the iPhone. And that would have a direct impact on Google's revenue stream. Therefore Google's licensing strategy with Android not only removes value from the OS level of the stack (directly hurting Microsoft and Palm/HP), but can be seen as a defensive play to keep any other OS from dominating the market and threatening Google's search advertising revenue.

More specifically, Google's business model may offer two general lock-in strategies that extend to the mobile space. First, rather than seeing Google's wide variety of offerings as intrinsically synergistic, they can rather be seen being a set of diverse hooks that anchor users to Google - none of which, except possibly search and Gmail, are particularly sticky. For each and every service it offers there are competitors and switching costs are not very high. The lack of stickiness drives Google to constantly experiment with and introduce other hooks for users. Second, what binds the entire Google empire together is its enormous stores of searchable databases, its ability to incredibly quickly serve this data and to match the appropriate advertisement to the content being requested. A key question for Google is whether it will be able to transfer its myriad services, each with their small hooks, into relevant mobile services that users want and that Google can monetize. The promise of 
mobile advertising is great, and Google's success with mapping and local business directory position it well for innovating around this new potential revenue stream. While lacking powerful stickiness, Apple's initially close relationship with Google was an important reason for the quick success of the iPhone, as one of the first and most important applications for the iPhone was to use Google Search (West and Mace 2010).

In the personal computer world, Google aimed to neutralize the centrality of the PC operating system (i.e., Microsoft but tangentially also Apple), in part by creating free cloudbased software that could run in a browser, regardless of the underlying OS or hardware. In the mobile Internet space, Google is adopting a similar goal, but with a different strategy: because of the lack of an installed OS base, there is an opportunity for it to provide a free smartphone operating system and thereby shift value away from OS and up higher in the stack to the Internet applications and online services it provides. This move can be seen as a way for Google to protect its single most important asset, online search, by blocking any other OS from getting sufficient market share to entertain the idea of moving away from Google's search function. The direct threat is from Microsoft and its Bing search engine, which with every Windows Phone OS that is sold will have Bing as the default search engine, thereby reducing Google's advertising dollars.

\section{Challenges for each competitor}

Nokia and the Symbian OS remain the overwhelming global smartphone leaders. This is a legacy of Nokia's brilliant conquest of the global mobile phone industry (Funk 2001; Steinbock 2001). The only nations where Nokia is not the dominant player are Korea, Japan, and the U.S. In Korea, this is because of the strength of Samsung and LG in their home markets. In Japan, the tight linkages between NTT DoCoMo, a set of unique standards, and the strong linkages to Japanese electronics have held Nokia at bay. In the process, Japan developed a unique smartphone ecosystem prior to any other nation (Funk 2001 ; 2003) that had a curious dual impact: First, it operated to exclude foreign firms. Second, it resulted in Japanese firms becoming captured in an early mover ecosystem that could not diffuse globally, but was very profitable. The final ecosystem that Nokia did not dominate was the U.S., which never enforced uniform standards and within which there were many competitors, but due to the market domination by the carriers. It is from the chaotic U.S. market and the Silicon Valley ecosystem that Nokia's most serious competitors, Apple and Google (and possibly HP/Palm) would emerge.

Nokia's strength as the dominant cell phone incumbent should not be underestimated. Only 2 years ago, the Nokia/Symbian global smartphone market share was enormous, but as Table 3 indicates it is rapidly losing market share. While it has critical complementary assets, including close relationships with many of the world's largest carriers, first-class manufacturing, deep technological capabilities, and rapidly increasing cell phone market share in the world's developing country markets, the threat to its domination are clear.

For Nokia there are a number of competencies that it must develop or recruit partners to provide to retain its dominance in the supersession by the smartphone of the mobile phone. Probably the most important competency is whether Nokia can leverage its deep knowledge of mobile telephones, carriers, strong supply chain and manufacturing to understand the Internet and its evolving dynamics. This has a geo-psychological component, as Silicon Valley is the center of the world's Internet industry (mashups, Web x.0, social networking, etc.), while Finland is better positioned as a high-end, high-quality supply chain and manufacturing nation. As the mobile Internet has become the dominant usage of the mobile 
Table 3 Global smartphone market share, 2006-2009 (adapted from West and Mace 2010; Canalys 2010)

\begin{tabular}{|c|c|c|c|c|}
\hline Plat form & 2006 & 2007 & 2008 & 2009 \\
\hline Symbian & $67 \%$ & $63.5 \%$ & $52.4 \%$ & $47.2 \%$ \\
\hline BlackBerry & $7 \%$ & $9.6 \%$ & $16.6 \%$ & $20.8 \%$ \\
\hline $\mathrm{iOS}$ & - & $2.7 \%$ & $8.2 \%$ & $15.1 \%$ \\
\hline Windows Mobile 7 & $14 \%$ & $12.2 \%$ & $11.8 \%$ & $8.8 \%$ \\
\hline Android & - & - & $0.5 \%$ & $4.7 \%$ \\
\hline $\operatorname{Linux}^{\mathrm{a}}$ & $6 \%$ & $9.6 \%$ & $7.6 \%$ & n.r \\
\hline Palm OS/webOS & $5 \%$ & $1.4 \%$ & $1.8 \%$ & $0.7 \%$ \\
\hline Other & $1 \%$ & $1.0 \%$ & $1.1 \%$ & $2.7 \%$ \\
\hline Android & - & - & $0.5 \%$ & $4.7 \%$ \\
\hline Total & $100 \%$ & $100 \%$ & $100.0 \%$ & $100.0 \%$ \\
\hline Annual total (millions) & 64.1 & 122.3 & 139.3 & 166.3 \\
\hline Smartphones/all handsets & $6.3 \%$ & $10.7 \%$ & $11.7 \%$ & $14.7 \%$ \\
\hline
\end{tabular}

${ }^{\mathrm{a}}$ Includes LiMo and firm-specific Linux efforts.

telephone, it remains to be seen whether Nokia can understand and deliver the services and experiences that consumers desire.

Nokia is facing difficulty as the locus of value creation in the smart phone is on the Internet. Because of the difficulties with Symbian, Nokia joined with Intel to develop a new operating system, Meego. For Meego to succeed, it had to not only support the hardware and applications that today's users expected, but it also had to be attractive to the development community. The key questions were whether other manufacturers would adopt the new Meego OS, or if it would become an isolated Nokia-Intel OS. However, in early 2011 Nokia decided to adopt Microsoft WP7. A decision that surprised many observers, as Windows Phone 7 trails both Apple and Google in market share.

Regardless of whether Nokia continues to use Windows Phone 7 or switches again later, the key question for Nokia is whether manufacturing excellence is still a strength, or a commodity? Its two most serious competitors, Apple and Google, do not have manufacturing operations. Apple contracts manufacturing out, while Google for its own phones contracts out manufacturing, but more important, with Android any manufacturer can simply adopt it with a very simple licensing agreement.

The challenges from the current smartphone aggressors, Google and Apple, differ profoundly. Essentially, the challenge from the iPhone is on the strength of its user interface, design, branding, and customer-facing ecosystem of apps and media available through the iTunes store. Given that Apple provides the device and has a strategy, as has been the case with the Macintosh, of excluding competitors in terms of hardware and critical software and intends to profit from hardware sales and application sales (through a tax on transactions), its threat to the incumbent device makers is, in the first instance, manageable, especially given the emphasis on the high-end, North American market. It might be possible for Nokia or other competitors to respond with their own online stores, offering equally user-friendly interfaces and similar quality operating systems, software, and services - not a trivial undertaking, but possible. With an adequate OS, it could try to draw Apple into price wars, destroying margins. Finally, with its strength in developing countries, it could flood those markets with its OS and remain a leader on the basis of sheer volume. This might attract developers for the different local markets. 
The more predictable and less worrisome possibility is that as long as Apple continues its walled-garden, high-cost strategy, it can make inroads, but not become a systemic threat. Even if Apple has a more vibrant ecosystem that attracts product and service providers, it is difficult to see Apple dominating the entire industry space or becoming a monopolist. Another outcome could be a turbulent, but meta-stable market such as the one that has emerged in game boxes where three oligopolists, Nintendo, Microsoft, and Sony compete fiercely, but none are annihilated because they continue to have robust ecosystems. An oligopolistic outcome, possibly with strong market segmentation, e.g., national regions or price categories, could provide room for Nokia and possibly a few other handset makers. For the strongest incumbents, Apple's challenge is symmetric, though this symmetry could possibly be upset by the introduction of the larger iPhone, the iPad, which threatens not only Amazon's Kindle, but also the netbook and eventually the PC notebook computer.

The Android challenge is asymmetric because Google is agnostic in almost all directions. In the first instance, it is purely interested in growth of traffic that it can monetize through advertising. The free operating system unfetters pure-play manufacturers from worrying about either building their own OS or licensing the OS from a direct competitor. Google can provide an elegant low-cost OS because Google's monetization strategy relocates value capture. The Android platform encourages new entrants of all sorts, and the seriousness of the challenge to both Nokia and Apple is clear. At an employee event, Apple CEO Steve Jobs is reported to have exclaimed, "We did not enter the search business. They entered the phone business. Make no mistake - they want to kill the iPhone" (Abell 2010).

It is difficult for dominant incumbents to respond to asymmetric challenges because they threaten to devalue some of their key competencies, while Google's business model is not directly threatened by them. The building of an ecosystem and platform adoption requires a compelling value proposition for potential adopters. Apple has no interest in adopting Android, but Nokia's situation was far more difficult after it decided to abandon Symbian. Given the rapidity with which Android in particular was occupying the "open" OS space, Meego was simply too late. This meant choosing between Android and WP7. With WP7, Nokia had greater leverage as Microsoft was willing to provide major benefits to Nokia in return for adoption that would provide WP7 with greater market share. However, Nokia's biggest problem is the "open" Android platform dramatically levels the playing field for second-tier handset and chip set developers who may not have strong brands or sufficient skills and market power to build and support an OS. The Google Android brand can be leveraged by these second-tier firms to compete against the established firms. These entrants include already important players such as Samsung and LG and new entrants particularly HTC that are creating enormous competition globally and then there may be other entrants at the regional level. All of these are effectively commoditizing the smartphone, driving down cost and encouraging adoption-all the while creating a larger market for Google advertisements. Finally, it is not only complementors that may create new products to further increase Android phone functionality - so can Google.

Android provides an increasingly attractive platform upon which applications can be built, thereby competing for developer attention with Apple. As is true on the Internet, Google's main revenue source on the mobile Internet will be advertising revenue. Depending upon how it handles access to the Android platform, it can afford not to extract rents from the application developers - a model that contrasts with Apple's onerous terms (Apple 2010). The Android business model also provides a platform that is not directly controlled by Google, thereby separating it from direct responsibility for the types of 
applications developed, but also suggesting that Google is unlikely to directly compete with third-party applications.

Nokia is in a difficult position. Though Symbian is now entirely open, and has widespread developer support and a huge global user base, it is a legacy OS and the initial plan was to abandon it for the more modern Meego. However, while Meego was likely to probably be elegant and very open, it was entering the market too late and to attract users in an environment where many ecosystem participants had already made OS-specific investments. For these reasons, Nokia abandoned Meego and adopted WP7. The reason for this is likely that Nokia recognized that the market was already locking-in and Meego was simply too late. The decision to adopt WP7 suggests that Nokia will be forced to compete as a manufacturer that does not control its software. Moreover, Microsoft will sell its software to Nokia's competitors, but most important Android is a less expensive OS than is WP7. The choice of Microsoft by Nokia does not upset Google's asymmetric value proposition for other smartphone makers and consumers. The stance of the carriers will be significant, but they are also constrained, as iPhone and Android have considerable consumer support, and, of course, Google is not an important factor in the handset market.

\section{Impact on other constituents in the value chain}

The outcome of the platform struggle will also have important implications for complementors and firms delivering other parts of the value proposition. One of the most important groups affected is the carriers. In many regions of the mobile telephony world, they are an enormously important part of the industry architecture because they sell the customer the phone with a service package. In this case they are the retail channel for the phone maker and can have great influence on the design and capabilities of the phone. The large carriers also develop network-specific services, many of which they own or they authorize application providers to offer particular services on their networks - the "walled garden" strategy. The mobile Internet allows customers to exit the garden, largely destroying the businesses inside the wall. The fear for carriers is that they will be reduced to a commodity in a competitive marketplace, resembling how the Internet destroyed the businesses of access providers such as AOL and Prodigy with their walled gardens. The mobile Internet is potentially a similar threat to network carriers.

In the U.S. market, Apple was able to wrest control of the user interface from AT\&T, a concession which carriers had been extremely reluctant to offer, but in return AT\&T got an exclusive relationship. Further, AT\&T gave Apple a share of all revenues, including the monthly service fee. For AT\&T, the iPhone relationship was extremely valuable, as it not only locked in new subscribers but also unleashed a large revenue stream from data downloads. Because of the exclusive contract with AT\&T, the enormous success of the iPhone meant that the other carriers lost customers to AT\&T. This required a response, but the incumbent mobile phone makers were not able to provide comparable smart phones.

In the U.S., Nokia had little market share, so when Google offered Android, the carriers and the phone makers felt a strong economic pressure to adopt as they needed a response to the iPhone. Windows Mobile was inferior to Android and appeared more costly. ${ }^{9}$ In many respects, for other members of the mobile telephony ecosystem, Android was the only viable choice - despite the fact that they feared it would commoditize their network. The

\footnotetext{
${ }^{9}$ There is considerable debate as to whether Android life-cycle costs for carriers could be higher than various alternatives. We cannot answer this question definitively so we omit this discussion.
} 
alternative was to lose market share and lucrative data download revenues. Moreover, since Google generates revenues through advertisements, it can share these ad revenues with carriers, thereby giving them a stake in encouraging more Android phones to use their network. Google's acquisition of AdMob helped make this possible (Frommer 2010). Recently, Apple has offered other carriers their own iPhones, a necessary response, as the other carriers were becoming all Android operations.

The mobile Internet affects other firms. Most recently, Adobe, the software firm behind Flash and Acrobat, has come under attack from Apple because decided not to support Flash software on the iPhone. Regardless of the technical reasons for the decision, it is significant because most PC-world Internet video is encoded in Flash. This was an also an attack upon Google because YouTube videos were traditionally offered in Flash, making them unavailable to iPhone users until Google agreed to encode its video also in a format (H.264) that iPhones could access. In contrast, Google immediately supported Flash on Android devices, effectively aligning Adobe with Android, though it also would support the other mobile OSs such as Symbian, Windows Mobile, and WebOS. ${ }^{10}$ While Adobe is not in itself critical, it shows other incumbent applications developers that Apple could be capricious in its relationships. Further, with the growth of Android market share, there would be a natural further alignment of Adobe with Google.

Google's Android, when considered in combination with the release of the Chrome OS, the transformation of Google Books to a commercial bookstore threatening Amazon, and its numerous other initiatives, may be just a small component of an overall strategy. While it is a platform, there may be no need for Google to directly monetize Android. In this scenario, Android serves only to block Apple from absorbing the entire mobile Internet space and threatening Google search. Thus Android catalyzes an ecosystem not in the control of Apple, Microsoft, or Nokia. This is sufficient for allowing Google to continue offering and proliferating the services driving its advertising monetization strategy.

For the firms defending their businesses and business models, forming alliances may be the best strategy. The first major move in this direction was the now-defunct Intel/Nokia Meego initiative . Other possibilities are combinations including Microsoft, Nokia, or HP, but, in any such alliances, one or both parties will have to surrender important assets. For Microsoft to drop the Windows franchise would be devastating to its business model. Nokia's decision to adopt WP7 places its fate in the hands of a ruthless monopolist on a platform that is not as open as Android. For HP, which is largely a device maker, joining Microsoft would be a return to the current arrangement in PCs. HP used Windows Mobile, so the losses might be minimal (except the $\$ 6$ billion spent on acquiring Palm). However, joining Windows is no different than joining the Android world. A combination of Nokia and HP makes little sense for either as they are device makers. So alliances, in theory, appear to be viable responses to the current competitive landscape faced by the incumbents, however strategically they are likely to be difficult to execute.

\section{Conclusion}

The mobile Internet competition is only in its early phases, and each of the key players brings significant competencies to the struggle. Moreover, it is entirely possible that all of

\footnotetext{
${ }^{10}$ On May 4, 2010, there were rumors that the Department of Justice would examine whether Apple was illegally forcing its applications suppliers to only produce for the iPhone. Apparently, this complaint was filed by Adobe, which is already abandoning the Apple platform (Cooper 2010).
} 
them could find niches within the industry and none become dominant. Because no dominant design has emerged, it is possible that a new entrant could develop a transformative business proposition. For example, Facebook, with its enormous user community, could join with an also-ran such as Palm WebOS and influence its community in that direction, or, for example, encourage adoption of the Bing search engine. This might dislodge Android and begin an effort to steer users away from the Google offerings, weakening its advertising cash flow. Because of the unsettled nature of the current contest and the complexity of the business space upon which these firms are competing, alliances and new business models threaten all the incumbents.

Apple has enormous advantages in the sense that it was the first mover and has continually been the aggressor moving from the iPod to the iPhone and now the iPad using an almost seamless user experience. These strengths and the momentum are powerful. Though the iOS devices allow users to access the entire Internet, the hardware exists in a closed platform of iTunes and the App Store. The popularity and elegance of Apple's product offer ample opportunity to application providers, but Apple's supreme power in the ecosystem places them in a vulnerable position. Unfortunately, this closed platform strategy is assailable and is now threatened by Google. Banishing Adobe, a very important complementor, from the iPhone world drove a neutral party with enormous software capabilities toward the Android world. Whether or not it is true that Flash would have allowed software vendors to sell directly to iPhone users and not be forced to go through the Apple App's store (Copeland 2010), it created an instant and unforeseen ally for Android.

The incumbent telephone device makers must decide which OS(s) they will support most vigorously. Their decisions appear to be quite constrained. Windows Phone will raise costs for the device makers, Apple will not license its OS, and the other possibilities are limited. Google's Android offers an attractive alternative that operators can adopt without fear that the sponsor Google will aggressively compete with them in handset sales. With Google accepting responsibility for maintaining the competitiveness of the Android OS, these firms can concentrate on creating new features and lowering price. For the other handset makers, Android provides them an expanding platform with software for which they do not have to pay. Further, with Google's market power and cachet, it removes their problem of deciding which OS is likely to be successful, thereby lowering their risk of investing scarce resources in a technological dead-end. Motorola, a fading leader, can adopt Android and compete with excellent designs. The emerging Asian manufacturing giants Samsung, LG, and HTC that have found it difficult to create globally acceptable software and user interfaces can use the global-class Android OS, and concentrate upon their manufacturing prowess and their ability to source a significant number of components inhouse. Android confronts Apple with a plethora of competitors; all of which are armed with a good OS and are willing to accept lower profit margins. Microsoft WP7, regardless of its quality, confronts an operating system for which makers, operators, and consumers do not have to pay anything up-front, but rather the consumers will pay for through a willingness to view advertising. For these traditional platform firms confronting competition from Google is difficult, because Google's business model is not directly dependent upon Android's acceptance or monetization. Google is successful if it prevents another OS from firms such as Apple, Nokia, or Microsoft from becoming dominant and thereby gaining leverage over Google's ability to extend its services into the mobile Internet space. Obviously, if Android becomes the dominant OS, Google will gain even greater power to monetize mobile Internet traffic.

Android's success demonstrates the difficulties of formulating strategy in the asymmetric competitive situations that are likely to become even more common in complicated layered stack competitions. Thus, for Google the greatest threats are likely to come from new 
competitors such as Facebook that can lever their strength in different parts of the stack and form alliances with existing firms such as Microsoft to attack other firms. This poses problems for platform theory, which recognizes that competitors may have different business models, but it accepts that the platform sponsor usually treats the platform as a source of direct value generation and/or capture. It is possible to speculate that the business models are legacies of the path-dependent evolutions of the firm and the sector within which they were dominant. This provides an, at least, partial explanation of the different business models as each firm enters the mobile Internet business. At the moment, no single dominant design has emerged, but Android is threatening to become dominant.

The platform literature captures the strategies of all of the rivals except Google and, too some degree, Apple. Apple, by not allowing complementors in manufacturing (it controls all manufacturing through outsourcing), strictly controlling application developers, and exclusively licensing operators, differs from the more open platform strategies discussed in most of the literature. Google has introduced a platform, but, at the moment, has undertaken none of the strategic initiatives one would expect if it was intending to monetize the platform. As mentioned earlier, for example, it has allowed operators to fork Android. ${ }^{11}$ It gives little support to and exerts little control over the applications community, allowing malware applications to emerge. While this strategy might change in the future if Android becomes dominant, this suggests that it is not pursuing a textbook platform strategy. It is impossible to generalize from a single case that is still evolving, but it indicates the possibility of using platforms, as auxiliaries to different value-capture strategies than has been understood in the platform literature.

Acknowledgements The authors acknowledge the assistance, discussions, and comments of Andrew Hargadon, Greg Linden, Jonathan Murray, Petri Rouvinen, Timo Seppälä, Urs von Burg, John Zysman, and two extremely thoughtful reviewers. We are particularly thankful to Joel West who contributed so much to the first version of this paper and without whose penetrating ideas and deep knowledge of the industry, we could never have completed the project. This research is a part of the ongoing collaboration of BRIE, the Berkeley Roundtable on the International Economy at the University of California at Berkeley, and ETLA, The Research Institute of the Finnish Economy.

\section{References}

Abell JC (2010) Google's 'Don't be evil' Mantra is 'Bullshit,' Adobe is lazy: apple's Steve Jobs (Update 2). Wired. http://www.wired.com/epicenter/2010/01/googles-dont-be-evil-mantra-is-bullshit-adobe-is-lazyapples-steve-jobs/\#ixzz0nYNqOVCC. Accessed 27 January 2011

Ahonen T (2010) Insiders' guide to mobile. http://www.lulu.com/product/ebook/insiders-guide-to-mobilefree-edition/14310370. Accessed 27 January 2011

Apple (2010) iPhone developer program license agreement. http://www.eff.org/files/20100302_iphone_dev_agr. pdf. Accessed 27 January 2011

Canalys (2010) http://www.canalys.com/pr/2010/r2010111.html. Accessed 27 January 2011

Christensen CM (1997) The innovator's dilemma: when new technologies cause great firms to fail. Harvard Business Press, Cambridge

Comscore (2011) ComScore Reports February 2011 U.S. Mobile Subscriber Market Share. http://www.comscore. com/Press_Events/Press_Releases/2011/4/comScore_Reports_February_2011_U.S._Mobile_Subscriber_ Market_Share?utm _source $=$ feedburner\&utm _medium $=$ feed $\& u t m \_$campaign $=$Feed $\% 3 \mathrm{~A}+$ comscore $+\%$ 28comScore\%2C+Inc.\%29. Accessed 1 April 2011

\footnotetext{
${ }^{11}$ The rapid pace of new releases was already dampening forking. However, in 2011 Google began to tighten licenses and forbidding forking or rewriting Android code to, for example, remove the Google search function The full implications of these new developments to Google's commitment to keep Android open are not yet clear.
} 
Cooper C (2010) Will Uncle Sam get Steve Jobs to Blink? http://www.cbsnews.com/8301-501465_16220004072-501465.html. Accessed 27 January 2011

Copeland MV (2010) Behind the Adobe-Apple cold war. http://tech.fortune.cnn.com/2010/01/29/behind-theadobe-apple-cold-war/. Accessed 27 January 2011

Cullen J, Shcherbakov O (2010) Measuring customer switching costs in the wireless industry. Unpublished paper. http://www.openinternetcoalition.com/files/OIC_Reply_Comments_Attachment_A.pdf. Accessed 27 January 2011

Cusumano M (2010) Technology strategy and management: the evolution of platform thinking. Commun ACM 53(1):32-34

Cusumano MA, Suarez F (2009) The role of services in platform markets. In: Gawer A (ed) Platforms, markets and innovation. Edward Elgar, Northampton

Cusumano MA, Yoffie DB (1998) Competing on internet time: lessons from Netscape and its battle with Microsoft. The Free, New York

Frommer D (2010) The real reason wireless carriers love android: Google is paying them to. http://www. businessinsider.com/the-real-reason-wireless-carriers-love-android-google-is-paying-them-to-20103\#ixzz0mzRyAfqC. Accessed 27 January 2011

Funk JL (2001) The mobile internet: how Japan dialed up and the West disconnected. ISI Publications, Pembroke

Funk JL (2003) Standards, dominant designs and preferential acquisition of complementary assets through slight information advantages. Res Policy 32:1325-1341

Gartner press releases (2011) (all accessed 1/2/11): Mobile market: http://www.gartner.com/it/page.jsp? id=1455314 Mobile phone sales: http://www.gartner.com/it/page.jsp?id=1466313 PC market: http:// www.gartner.com/it/page.jsp?id=1479114 All accessed January 27, 2011.

Gawer A (2009) Platforms, markets and innovation. Edward Elgar, Cheltenham

Gawer A, Cusumano MA (2002) Platform leadership: how Intel, Microsoft, and Cisco drive industry innovation. Harvard Business School Press, Boston

Gawer A, Henderson R (2007) Platform owner entry and innovation in complementary markets: evidence from Intel. J Econ Manage Strategy 16(1):1-34

Ishii K (2004) Internet use via mobile phone in Japan. Telecommun Policy 28(1):3-58

Jacobides MG, Knudsen T, Augier M (2006) Value creation, value appropriation and the role of industry architectures. Res Policy 35:1200-1221

Kushida KE, Zysman J (2009) The services transformation and network policy: the new logic of value creation. Rev Policy Res 26(1-2):173-194

Martinez-Salazar MA (2010) The mobile phone user: identifying top mobile applications. http://ssrn.com/ abstract=1691210. Accessed 27 January 2011

Nokia (2010) Nokia Q4 2010 net sales EUR 12.7 billion, non-IFRS EPS EUR 0.22. http://www.nokia.com/ press/press-releases/showpressrelease?newsid=1482864. Accessed 31 January 2011

Pisano G, Teece DJ (2007) How to capture value from innovation: shaping intellectual property and industry architecture. Calif Manage Rev 50: 278-296

Steinbock D (2001) The Nokia revolution: the story of an extraordinary company that transformed an industry. Random House, New York

Tee R, Gawer A (2009) Industry architecture as a determinant of successful platform strategies: a case study of the I-Mode mobile internet service. Eur Manage Rev 6:217-232

Teece DJ, Pisano GP, Shuen A (1997) Dynamic capabilities and strategic management. Strateg Manage J 18:509-533

Wallace J, Erickson J (1992) Hard drive: Bill Gates and the making of the Microsoft Empire. Wiley, New York

West J, Mace M (2010) Browsing as the killer app explaining the rapid success of Apple's iPhone. Telecommun Policy 34(5-6):270-286

West J, O'Mahony S (2008) The role of participation architecture in growing sponsored open source communities. Ind Innov 15(2):145-168 